Artículo

\title{
Inducción de brotes a partir de varas florales de la orquídea Phalaenopsis spp. (Blume) in vitro
}

\author{
Karla Andrea Frausto Jaime ${ }^{1}$ \\ Ma. Del Carmen Ojeda Zacarías ${ }^{1 \S}$ \\ Omar Guadalupe Alvarado Gómez ${ }^{2}$ \\ Eduardo Alejandro García Zambrano ${ }^{2}$ \\ Humberto Rodríguez Fuentes ${ }^{2}$ \\ Gilberto Rodríguez Pérez ${ }^{3}$
}

${ }^{1}$ Facultad de Agronomía-Universidad Autónoma de Nuevo León-Unidad Marín. Carretera Zuazua-Marín km 17.5, Marín, Nuevo León, México. CP. 66700. Tel. 81 13404399. (k.frausto.jaime@ gmail.com). ${ }^{2}$ Facultad de Agronomía-Universidad Autónoma de Nuevo León-Campus Ciencias Agropecuarias. Francisco Villa s/n, Col. Ex-Hacienda El Canadá, Gral. Escobedo, Nuevo León, México. CP. 66050. Tel. 81 13404399. (omaralvarado@prodigy.net.mx; hrodrigu10@yahoo.com.mx; grodriguez263@hotmail.com). ${ }^{3}$ Instituto Tecnológico de Roque. Carretera Celaya-Juventino Rosas km 8. Celaya, Guanajuato. CP. 38110. Tel. 461 6115903. (eagarci1@ hotmail.com).

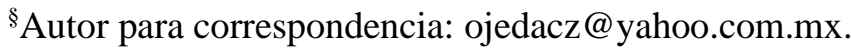

\section{Resumen}

La inducción de brotes in vitro es una estrategia de la micropropagación vegetal utilizada para incrementar la producción de orquídeas, en comparación con el cultivo tradicional que requiere un amplio periodo de tiempo para obtener una población sustancial para comercialización. El objetivo de este estudio fue inducir la formación de brotes in vitro a partir de las yemas florales de la orquídea Phalaenopsis spp., mediante una ruta de organogénesis. Se evaluaron cuatro formulaciones de sales minerales (MS al 100\%, MS al 50\%, Knudson y Fertilizante NPK 18-918/15-30-15) y cuatro variedades de Phalaenopsis spp. para determinar la viabilidad de los explantes. Se evaluaron dos reguladores de crecimiento (6-bencilaminopurina BAP $20.2 \mu \mathrm{M}$ solo y combinado con ácido naftalenacético ANA $5.37 \mu \mathrm{M}$ ), para determinar la inducción de brotes. Los resultados indican que la oxidación en los explantes depende de las sales minerales de los medios de cultivo, así como de la variedad de orquídea; la inducción de brotes depende del regulador de crecimiento empleado. Los reguladores BAP/ANA produjeron 2.4 brotes por yema contra 2 en BAP. El medio MS 50\% resultó ser la mejor opción para mantener la viabilidad de las yemas florales.

Palabras clave: Phalaenopsis, micropropagación, organogénesis.

Recibido: julio de 2019

Aceptado: septiembre de 2019 


\section{Introducción}

La familia Orchidaceae se conocen desde hace miles de años y desde entonces han tenido gran valor para el ser humano. En la actualidad son apreciadas alrededor de todo el mundo como plantas de ornato debido a sus flores, que es la parte más llamativa la cual presenta una gran variedad de formas, colores y aromas, estas características otorgan una alta demanda comercial para ser utilizadas en todo tipo de arreglos florales o para su venta como planta de interior.

Las orquídeas son plantas que pertenecen a la familia Orchidaceae, la más numerosa del reino vegetal con alrededor de 27000 especies registradas y distribuidas en casi todo el mundo (Campbell, 2013). A pesar de esta gran variedad sólo unos pocos géneros son aprovechados comercialmente en el mercado ornamental. Uno de los géneros más apreciados es Phalaenopsis, conocida comúnmente como orquídea mariposa, el cual presenta una gran diversidad en color y tamaño de sus flores, lo que conlleva a una gran demanda en el mercado ornamental.

Sin embargo, su propagación tradicional es complicada y demanda un largo periodo de tiempo, para obtener un hijuelo la planta madre debe tener al menos uno o dos años; además su reproducción sexual se ha visto afectada por la esterilidad de algunos de sus híbridos relacionada con los extensivos trabajos de hibridación en este género (Tirado et al., 2005). Por los factores antes mencionados surge la necesidad de hacer uso de nuevas tecnologías para su propagación.

El cultivo de tejidos vegetales es una técnica utilizada para la producción comercial de orquídeas y representa una solución para disminuir el tiempo de regeneración e incrementar las poblaciones para el comercio, ya que permite obtener un gran número de plantas, ya sea a partir de la germinación de semillas o de otro tipo de explante, a través de técnicas de propagación in vitro para determinar la capacidad organogénica y embriogénica, que son específicas de cada especie.

Algunos géneros producidos por esta técnica son: Phalaenopsis, Oncidium, Cymbidium, Dendrobium y Paphiopedium, (Chang y Chang, 1998; Flores et al., 2008). La principal razón de usar la micropropagación en orquídeas es porque permite obtener clones somáticos a partir de los cuales se regeneran plantas completas con características uniformes.

Los explantes utilizados son segmentos de varas florales, segmentos de hojas, semillas maduras, rizomas, y cuerpos semejantes a protocormos PLBs (Chang y Chang, 1998; Nayak et al., 2002; Feria et al., 2007; Arditti, 2008; Salazar et al., 2013). Para la propagación in vitro de orquídeas se han utilizado varios medios de cultivo como el Murashige y Skoog MS (Murashige y Skoog, 1962), B5 (Gamborg et al., 1968), Nuevo Medio Dogashima NMD (Tokuhara y Mii, 1993), Vacin y Went VW (Vacin y Went, 1949), Knudson C KC (Knudson, 1946) y el medio Hyponex (Nishimura, 1982), a los que comúnmente se les adicionan vitaminas, reguladores de crecimiento, agentes antioxidantes, entre otros compuestos, dependiendo de la etapa de micropropagación.

Se han desarrollado varios métodos de micropropagación mediante morfogénesis directa e indirecta en este género como la propagación clonal a través de cultivo de hojas, cultivo de yemas florales, así como la inducción de callo embriogénico y el cultivo de células en suspensión. Los principales tópicos a evaluar son el índice de sobrevivencia, la inducción de protocormos y la formación de plántulas, buscando una alta frecuencia de regeneración con la mayor homogeneidad entre plantas. 
Para la micropropagación se pueden seguir diferentes vías de multiplicación, una de ellas es la organogénesis directa, utilizada comúnmente en Phalaenopsis (Park et al., 2002). Esta técnica consiste en estimular la formación de brotes múltiples vegetativos por yema, los cuales se forman de novo de acuerdo al potencial morfogenético de los meristemos adventicios.

Para ello, los medios de cultivo deben estar complementados con reguladores de crecimiento en una relación tal que estimule al explante a producir dichos brotes; esta relación varía de acuerdo con la especie o híbrido con que se esté trabajando. Las estructuras polares que se formen generarán plántulas para ser utilizadas como fuente de explantes para la micropropagación, o ser llevadas hasta aclimatación (Krikorian, 1991; Merino, 2014). Uno de los protocolos exitosos que permite obtener flores uniformes consiste en estimular la formación de hojas a partir de los nudos de tallos florales para posteriormente inducir la formación de PLBs (Tanaka, 1992).

Sin embargo, a pesar de los protocolos desarrollados para el cultivo in vitro para Phalaenopsis, no todos los genotipos responden de la misma manera bajo condiciones idénticas de cultivo, por lo que deben ser ajustados a la respuesta de cada híbrido (Park, et al., 2002). Sin embargo, cada autor afirma con frecuencia proveer el mejor método de micropropagación para obtener una producción masiva con fines comerciales por lo que es difícil determinar mediante una revisión bibliográfica qué método es realmente el mejor ya que todos varían tanto componentes del medio de cultivo como explantes e incluso factores ambientales.

Por ello y sumado a que en el país no hay una amplia investigación al respecto, es necesario proveer resultados de experimentos realizados en México y adecuarlos a las necesidades y recursos. Si bien, esta técnica es empleada para la producción comercial de orquídeas en otros países, en México es una oportunidad de crecimiento para pequeños y grandes productores de orquídeas, ya que existen solo unas pocas empresas que han aplicado esta tecnología en sus instalaciones pero sin lograr cubrir la demanda del mercado, por lo que los grandes productores de orquídeas en el país se ven obligados aún a importar plántulas y los pequeños productores van incrementando sus poblaciones de manera paulatina.

Resulta necesario para el mercado ornamental de orquídeas de nuestro país, impulsar la producción de plántulas en territorio nacional para con ello, generar nuevos empleos, disminuir la dependencia al extranjero, e impulsar el desarrollo de la floricultura mexicana.

En la industria ornamental de orquídeas son pocos los países que cubren la demanda global, México puede ingresar a este mercado, puesto que cuenta con los climas apropiados para el desarrollo de diversas especies, a pesar de ello existen pocos invernaderos dedicados al cultivo de orquídeas en el país. Siendo así, se ha realizado un gran esfuerzo, mediante el cultivo in vitro, en asegurar la propagación y conservación de especies endémicas, pero hay pocos resultados para las especies con potencial comercial.

Puesto que las orquídeas tienen un potencial organogénico en las yemas florales, se planteó aprovechar dicho potencial para obtener una inducción clonal mediante un apropiado balance hormonal en el medio de cultivo. Por lo que fue necesario: establecer asépticamente los explantes de la orquídea mariposa en condiciones in vitro; determinar el medio de cultivo adecuado para mantener los explantes establecidos de Phalaenopsis viables y definir el balance hormonal que permita la inducción de brotes vegetativos en las yemas florales de esta orquídea. 


\section{Materiales y métodos}

El estudio se llevó a cabo en el Laboratorio de Biotecnología Vegetal de la FAUANL en Marín, NL. Fueron utilizados como fuente de explantes los escapos florales de cuatro variedades de orquídeas Phalaenopsis spp. crecidas en condiciones de invernadero por un año que corresponden a $P$. amabilis, $P$. Kaleidoscope, $P$. Taisuco x Sogo, $P$. Taipei Gold (Chang y Veilleux, 2009) (Figura 1). Las plantas madre se mantuvieron durante un mes en condiciones controladas de luz y temperatura, con riego y fertilización constante con aplicaciones de 15-30-15 NPK (nitrógenofósforo-potasio).
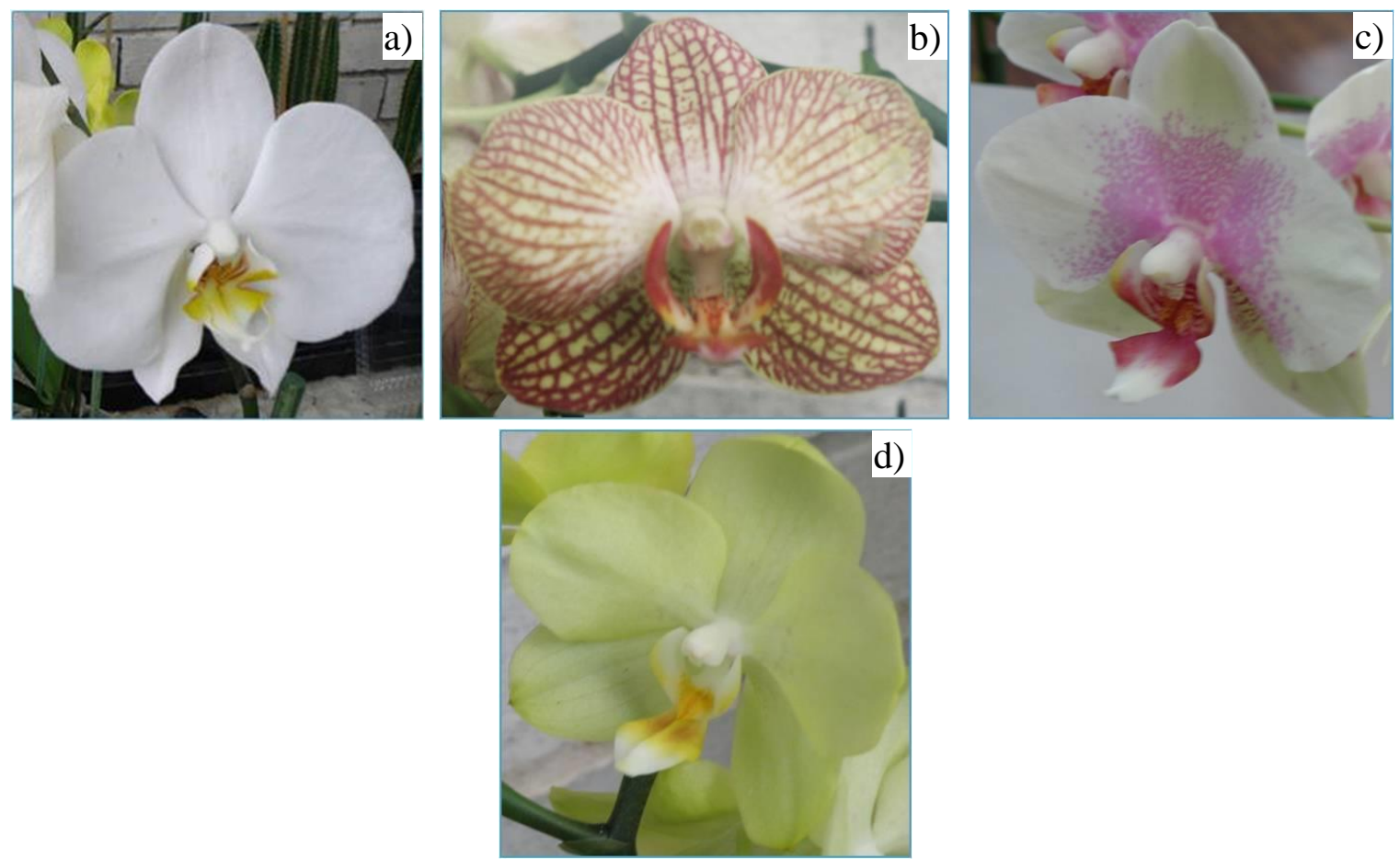

d)

Figura 1. a) orquídea blanca (P. amabilis); b) orquídea rayada (P. Kaleidoscope); c) orquídea rosa ( $P$. Taisuco x Sogo); y d) orquídea amarilla (P. Taipei Goid).

La desinfección inicio con el lavado de las varas florales en una solución jabonosa para lo cual se utilizó un cepillo dental de cerdas suaves para no dañar el tejido vegetal, se eliminaron con cuidado las brácteas, y se realizó un enjuague con abundante agua potable. En seguida se sumergieron las varas por 15 min en agua destilada con 15 gotas $\mathrm{L}^{-1}$ de una solución de plata coloidal $0.32 \%$. En estas condiciones se trasladaron a la campana de flujo laminar y en condiciones de asepsia se cortaron en segmentos de aproximadamente $1 \mathrm{~cm}$ de longitud de tal manera que cada yema quedó en el centro del segmento vegetal, a excepción de las yemas apicales que el $1 \mathrm{~cm}$ de longitud quedó debajo del ápice, se utilizaron todos los nudos florales.

Se sumergieron en etanol al 70\% por dos minutos, y en seguida se pasaron a una solución de $\mathrm{NaClO}$ $1 \%$ con dos gotas de tween 20 por cada $100 \mathrm{~mL}$ de solución, permaneciendo por $10 \mathrm{~min}$. Concluido el tiempo se realizaron tres enjuagues con agua bidestilada esterilizada. En caso de presentarse daño tisular en los bordes del explante éste fue retirado con un bisturí sobre una placa Petri. Finalmente se establecieron los explantes en los medios de cultivo de cada tratamiento. 
Se realizaron dos experimentos, uno sobre sales minerales y otro sobre organogénesis. Para determinar las sales minerales más viables se evaluaron cuatro medios de cultivo: MS al 50\% de sus sales, MS completo de sales, medio con sales de Knudson C, y una mezcla de dos Fertilizantes 18-09-18/15-30-15 NPK, 1 g de cada uno. Para evaluar la capacidad organogénica se utilizaron explantes de P. amabilis y se establecieron dos tratamientos en medio MS al 50\% con diferentes reguladores de crecimiento: el primero fue únicamente 6-Bencilaminopurina (BAP) $20 \mu \mathrm{M}$ y el segundo consistió en una combinación de 6-Bencilaminopurina (BAP) $20 \mu \mathrm{M}$ y ácido naftalenacético (ANA) $5.37 \mu \mathrm{M}$.

Los medios de cultivo se complementaron con $100 \mathrm{mg} \mathrm{L}^{-1}$ de mioinositol, $0.1 \mathrm{mg} \mathrm{L}^{-1}$ de tiamina, $0.5 \mathrm{mg} \mathrm{L}^{-1}$ de ácido nicotínico, $0.5 \mathrm{mg} \mathrm{L}^{-1}$ de piridoxina, $2.0 \mathrm{mg} \mathrm{L}^{-1}$ de glicina, $30 \mathrm{~g} \mathrm{~L}^{-1}$ de sacarosa, $10 \mathrm{mg} \mathrm{L}^{-1}$ de ácido cítrico, $8 \mathrm{~g} \mathrm{~L}^{-1}$ de Agargel y se ajustó el $\mathrm{pH}$ a $5.8 \pm 0.02$ usando $\mathrm{NaOH}$ o $\mathrm{HCl}$ $1 \mathrm{~N}$, se esterilizaron en autoclave a $121^{\circ} \mathrm{C}$ a 1.5 atmósferas de presión durante $15 \mathrm{~min}$. Las yemas o unidades experimentales in vitro se mantuvieron por 16 semanas en condiciones de incubación controladas bajo una intensidad lumínica de $24-27 \mu \mathrm{M} \mathrm{m}^{-2} \mathrm{~s}^{-1}$ con fotoperiodo 16 horas luz y ocho de oscuridad a una temperatura de $24^{\circ} \mathrm{C} \pm 2{ }^{\circ} \mathrm{C}$.

Ambos experimentos quedan establecidos con un diseño estadístico completamente al azar el cual se expresa como $Y_{i j}=\mu+T_{i}+E_{i j}$. El experimento de sales minerales mantuvo un arreglo factorial 4 x 4, donde el factor A son los medios de cultivo y el factor B son las variedades; se evaluó la variable de porcentaje de oxidación y los datos se analizaron mediante estadística no paramétrica con el método de chi-cuadrada $\left(\mathrm{X}^{2}\right)$.

En el experimento de multiplicación se evaluaron las variables de porcentaje de inducción y número de brotes, los datos se analizaron mediante $\mathrm{X}^{2}$ y análisis de varianza respectivamente. Se utilizó el programa estadístico Statistical Package for the Social Sciences (SPSS) para el análisis de datos.

\section{Resultados y discusión}

Transcurridos ocho días del establecimiento se obtuvo $75 \%$ de sobrevivencia al método de desinfección empleado en los explantes del primer experimento. Respecto a los medios de cultivo se observó gran variabilidad en la oxidación de los explantes, al considerar un explante oxidado aquel que pierde su coloración verde y cambia a tonalidades de amarilla a canela, con o sin necrosis, ya que un tejido que no expresa el color verde es indicativo de ausencia de cloroplastos, organelos básicos para generar energía suficiente para las funciones celulares (Taiz y Zeiger, 2006).

Se observaron secreciones de color café en el medio de cultivo (Figura 1), característico de compuestos fenólicos que al no poder dispersarse afectan a las células del explante continuamente, lo cual contribuye al proceso de oxidación, por esta razón se decidió realizar subcultivos a medio nuevo cada tres semanas. 


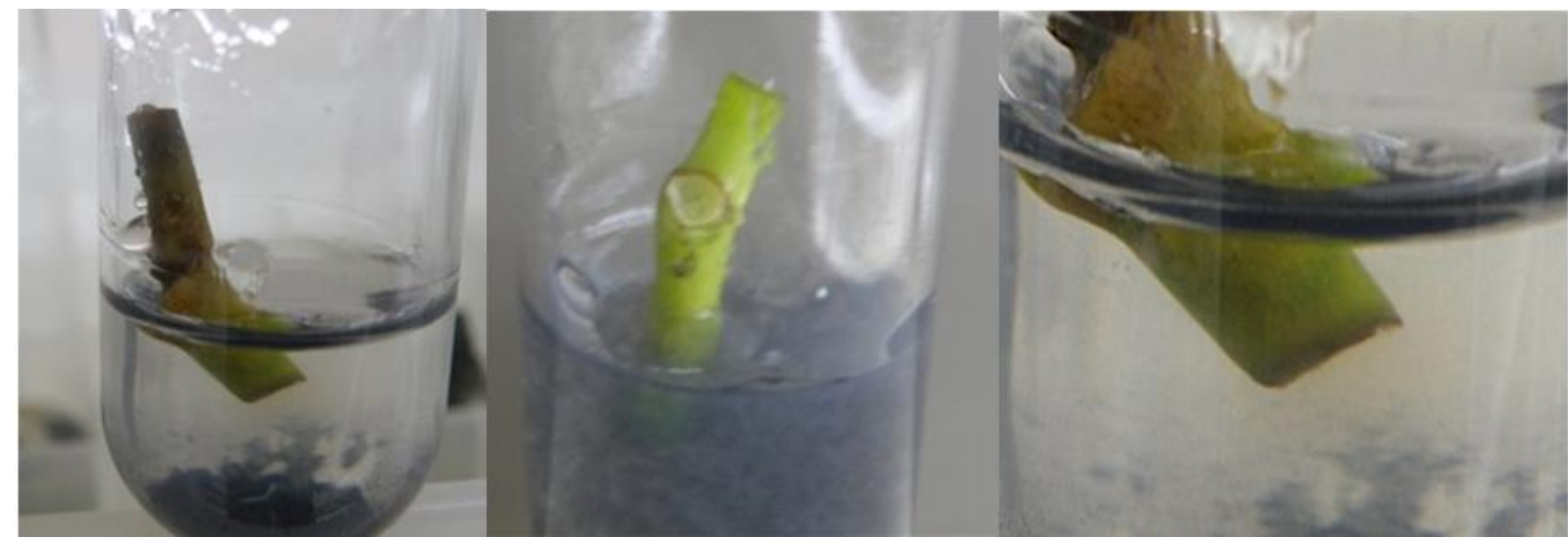

Figura 2. Oxidación de explantes. Izquierda: yema que presenta oxidación; centro: yema que se considera viable; derecha: compuestos fenólicos liberados al medio de cultivo.

Al evaluar los resultados con el estadístico chi-cuadrada se observó que la oxidación en los explantes depende del medio de cultivo utilizado (Cuadro 1).

Cuadro 1. Porcentaje de oxidación de explantes por medio de cultivo.

\begin{tabular}{cc}
\hline Medio de cultivo & Porcentaje de oxidación $^{\mathrm{a}}$ \\
\hline MS 50\% & $11 \%$ \\
Knudson C & $67 \%$ \\
MS 100\% & $75 \%$ \\
Fertilizante & $100 \%$ \\
\hline
\end{tabular}

${ }^{a} X^{2}=16.714 \operatorname{con} p<0.05$.

Es importante resaltar que el MS 100\%, aunque es un medio muy completo al contener macro y micro elementos, es un medio con una alta cantidad de sales, y como menciona Krikorian (1991), esto puede ser sustentable para el crecimiento de ciertos cultivos que requieren concentraciones altas de iones, bajo el supuesto que todos los microelementos conocidos y necesarios para las plantas completas lo son también para las células y tejidos cultivados; sin embargo, las orquídeas mantienen un bajo requerimiento mineral debido a que han evolucionado en algunos aspectos que las ayudan a sobrevivir en medios de poca disponibilidad de agua y nutrientes, como sus hojas gruesas, raíces con velamen, pseudobulbos, entre otros (Gottschalk, 2012).

En contraste, el MS 50\% resultó más favorable para mantener la viabilidad de los explantes, ya que mantuvo los mismos macros y microelementos, pero a una concentración reducida. El medio de Knudson mantiene la misma relación 1:2 de amonio: nitrato que el MS, pero difiere en la fuente de nitrógeno, y es por ello que suele utilizarse para evaluar el crecimiento como respuesta a la nutrición nitrogenada (González et al., 2012); sin embargo, no contiene los microelementos que proporcionan las sales de MS, como el zinc, sodio y cobre, los cuales se sabe, se acumulan en raíces u hojas en cultivos de Phalaenopsis en hidroponía o en musgo de sphagnum (Trelka et al., 2010). 
El medio elaborado con fertilizantes mantiene una concentración de sales alta y tampoco suministra microelementos. Diversas investigaciones como las de Park et al. (2002); Gow et al. (2008), en las que estudian diferentes respuestas in vitro en Phalaenopsis, han sido realizadas con predilección por el MS 50\% como medio basal, sin embargo, hacen falta estudios detallados de los requerimientos de microelementos en Phalaenopsis y en muchas otras orquídeas. Con respecto a la variedad, se observó que la misma influye en la viabilidad de los explantes (Cuadro 2).

Cuadro 2. Porcentaje de oxidación de explantes por variedad de Phalaenopsis.

\begin{tabular}{cc}
\hline Variedades & Porcentaje de oxidación $^{\mathrm{a}}$ \\
\hline Phalaenopsis amibilis & $25 \%$ \\
Phalaenopsis Taipei Gold & $67 \%$ \\
Phalaenopsis Kaleidoscope & $78 \%$ \\
Phalaenopsis Taisuco x Sogo & $100 \%$ \\
\hline
\end{tabular}

${ }^{\mathrm{a}} \mathrm{X}^{2}=13.810$ con $p<0.05$.

Con anterioridad, Brandelli y Lopes (2005) han demostrado la relación entre el oscurecimiento de duraznos (Prunus persica) y la actividad de la enzima polifenol oxidasa (PPO). Esta enzima se encarga de catalizar la reacción entre los compuestos fenólicos producidos por los explantes y el oxígeno molecular que genera quinonas, sustancias muy reactivas que inhiben el crecimiento, ocasionan daño o incluso la muerte del tejido (He et al., 2009).

Scalzo et al. (2005) demostró diferencias en el contenido de fenoles entre diferentes genotipos de fresa (Fragaria x ananassa), albaricoque (Prunus armeniaca L.) y durazno (Prunus persica L.) y Pequeño et al. (2015) relaciona el contenido de fenoles y la actividad de la PPO con el genotipo en Jatropha curcas in vitro.

En este estudio se registró una gran variabilidad en la oxidación entre variedades por lo que podría evaluarse la actividad de la PPO bajo diferentes tratamientos antioxidantes. Aun cuando $P$. amabilis mantiene mayor adaptabilidad al establecimiento in vitro que los otros híbridos, se deben considerar otros factores que no han sido evaluados en este experimento, como el estado fisiológico de las plantas madre, régimen de fertilización, riego, intensidad lumínica, humedad, entre otros, como en el que estuvieron en el invernadero de su procedencia, por lo que el estrés provocado por la alteración de estos y demás factores, sumado al traslado, dieron como resultado la acumulación de estrés en las plantas donadoras de explante de las cuatro variedades, lo que es notable tanto en la sequedad de sus raíces, como marchitez de la punta de las hojas.

George et al. (2008) menciona que una elección adecuada del material vegetal puede tener un efecto importante en el éxito del cultivo de tejido in vitro. Es por ello que, para reducir el estrés, se mantuvieron las plantas madre durante un mes antes del experimento en condiciones de aclimatación, con luz y temperatura controladas, así como con riego y fertilización frecuente. Sin embargo, si se considera el lento crecimiento característico de varios géneros de orquídeas (Cumo, 2013), se define que el tiempo de aclimatación no fue suficiente para las demás variedades, por lo cual se sugiere extender el tiempo de aclimatación a dos meses, después de terminada la floración, pues en este momento la planta ha pasado por el gasto energético de la producción de flores y comienza un nuevo periodo de crecimiento vegetativo. 
La calidad de las plantas donadoras es un factor crítico que subsecuentemente afectará el rendimiento del cultivo in vitro, por lo que, es recomendable estandarizar las condiciones de crecimiento tanto como sea posible (Preece, 2008). Así también, se recomienda el uso de agentes antioxidantes durante el establecimiento como el ácido ascórbico, o de otros agentes como el carbón activado, los cuales son incorporados al medio de cultivo para controlar el proceso de oxidación (Ibarra et al., 2016). En el experimento sobre la inducción de brotes se observa que la respuesta de los explantes depende del regulador empleado (Cuadro 3).

Cuadro 3. Porcentaje de inducción de explantes y número de brotes por explante de acuerdo al regulador de crecimiento empleado en $P$. amabilis.

\begin{tabular}{ccc}
\hline Regulador de crecimiento & Porcentaje de inducción $^{1}$ & Núm. de brotes $^{1}$ \\
\hline BAP & $5 \%$ & $2 \mathrm{a}$ \\
BAP/ANA & $33 \%$ & $2.4 \mathrm{a}$ \\
\hline
\end{tabular}

$\mathrm{BAP}=6$-Bencilaminopurina. ANA $=$ ácido naftalenacético. ${ }^{1} \mathrm{X}^{2}=16.714$ con $p<0.05$. a $=$ diferencia de medias por Tukey.

Asimismo, la influencia de las auxinas y citocininas es evidenciada en los resultados de inducción puesto que una pequeña cantidad de auxina puede potencializar el efecto de la citocinina, tal como lo describe Krikorian (1991). A pesar de dichas afirmaciones y puesto que varias auxinas parecen tener diferentes sitios de acción, sería conveniente ensayar combinaciones más extensivas y evaluar diferentes auxinas con diferentes citocininas.

Las propiedades del explante también rigen el crecimiento in vitro, pues está bien establecido que diferentes genotipos pueden no responder de la misma manera aunque se encuentran en el mismo medio de cultivo, es por ello que res necesario innumerables estudios empíricos para optimizar medios para diferentes especies e inclusive para cultivares de la misma especie puesto que la capacidad de regeneración es específica para cada especie (Salgado et al., 2007; Preece, 2008).

Los resultados obtenidos en la multiplicación resultan poco competitivos para una producción a gran escala que sea sustentable para los productores nacionales, ya que autores como Košir et al. (2004); Gow et al. (2008) han logrado obtener por organogénesis directa hasta 8 y 15 brotes por explante respectivamente (Figura 3 ).

Nuevamente, aunque la causa puede ser multifactorial, se considera al estado fisiológico de las plantas donadoras el de mayor influencia ya que éste influye en la capacidad morfogenética del explante, además que los requerimientos nutricionales y hormonales difieren en los tejidos cultivados que provienen de plantas en diferentes edades fisiológicas (Villalobos y Torpe, 1991).

Otro factor importante es la elección de las yemas florales en la vara floral, en este estudio se emplearon todos los nudos florales, no obstante, no se logró la desdiferenciación en las yemas terminales (Figura 4). Jiménez y Guevara (1996) mencionan que las yemas intermedias son las más adecuadas y las que tendrán mayor posibilidad de resistir el proceso de establecimiento aséptico y producir un brote debido a que en ellas se concentran una mayor cantidad de reguladores endógenos, además consideran que el primer nudo basal no presenta yema axilar mientras que las yemas terminales tienen un alto grado de diferenciación hacia el estado reproductivo, por lo que las yemas intermedias son las más adecuadas para inducir el crecimiento vegetativo. 


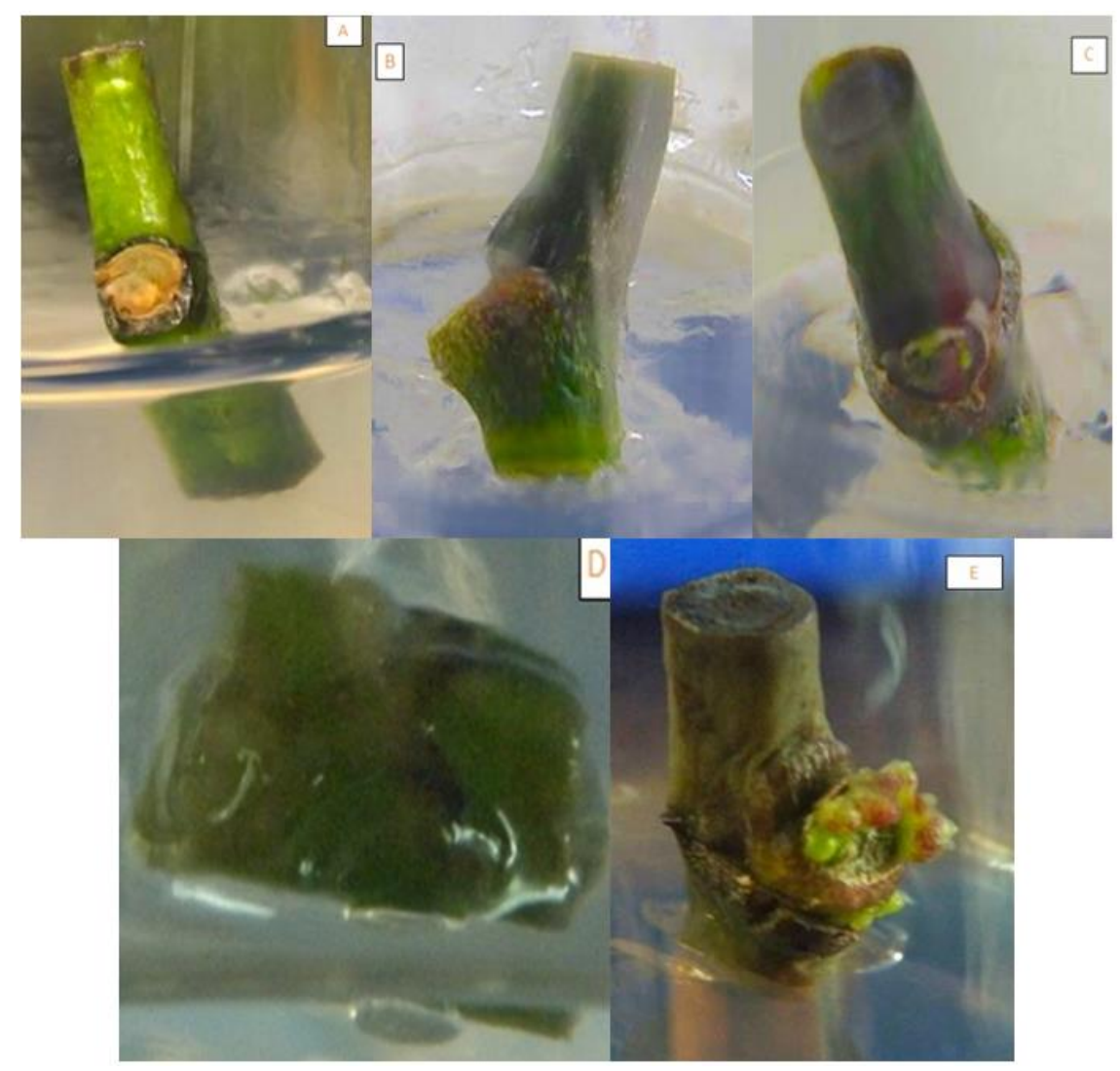

Figura 3. Inducción de brotes en yemas florales de la orquídea Phalaenopsis. A) yema durmiente a las 2 semanas; B) ensanchamiento de parte inferior de yema durmiente a las 4 semanas; C) formación de brotes en yema axilar a las 6 semanas; D) formación de brote en yema axilar a 10 semanas; E) brotes vegetativos desarrollados en yema durmiente a 14 semanas. A, B y C corresponden al tratamiento con BAP, D y E al tratamiento con BAP/ANA.

Coincidiendo, Park et al. (2002) recomiendan emplear entre el segundo y cuarto nudo del tallo floral a partir de la base y que contengan siempre una yema lateral diferenciada. Por el contrario, Košir et al. (2004) obtuvieron una micropropagación rápida al emplear nudos con yemas durmientes (Figura 4).

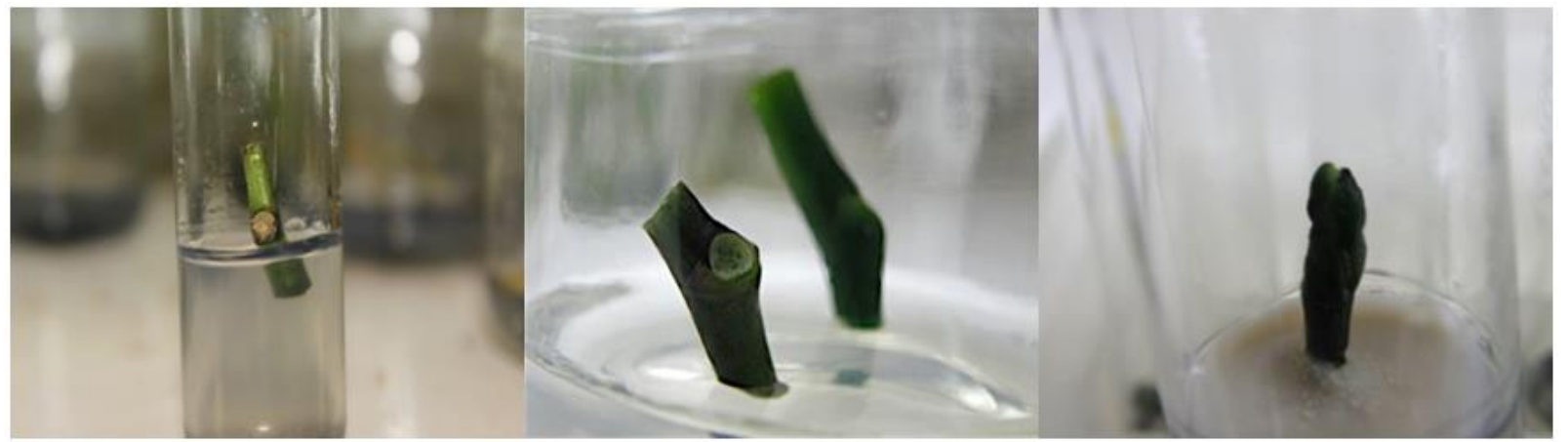

Figura 4. Yemas florales establecidas. Izquierda: yema durmiente del extremo superior de la vara floral; centro: yemas activas del centro de la vara floral; derecha: yema apical de la vara floral. 
Aunque otros factores físicos como la luz también deberían ser analizados, solo mediante una caracterización rigurosa del material biológico se puede estimar y comprender el rango y la magnitud de la variación. Hay que considerar que al momento de emplear la micropropagación la regulación hormonal dependerá no solo del genotipo propio de la especie elegida, sino también de los estímulos físicos del ambiente, por lo que la respuesta se verá afectada por la concentración y la proporción de cada hormona empleada.

\section{Conclusiones}

Con respecto al primer experimento de la orquídea mariposa se concluye que: a) las sales minerales empleadas en los medios de cultivo, así como la variedad de orquídea Phalaenopsis influyen significativamente en la oxidación de los explantes; y b) la mayor viabilidad de explantes se logró en el medio MS 50\%.

Con respecto al segundo experimento se puede afirmar que la organogénesis en la orquídea $P$. amabilis se obtiene cuando se establecen sus explantes en el medio de cultivo adecuado y con un correcto balance hormonal, por lo tanto, la atención a factores como la combinación e interacción de los reguladores de crecimiento y sus concentraciones durante el cultivo de sus tejidos, permitió la multiplicación clonal in vitro de esta orquídea.

Se concluye además que: a) Los balances hormonales empleados, ya sea BAP $20 \mu \mathrm{M}$ o bien BAP $20 \mu \mathrm{M} / \mathrm{ANA} 5.37 \mu \mathrm{M}$, en medio MS 50\%, permiten la inducción de brotes en las yemas florales de esta orquídea; y b) Sin embargo, la combinación de ambos reguladores incrementa significativamente la inducción. Por lo tanto, es más adecuado combinar los reguladores para obtener mayor número de explantes con respuesta con un buen número de brotes.

Es conveniente evaluar diferentes concentraciones y combinaciones de ambos reguladores de crecimiento, así como evaluar diferentes auxinas con diferentes citocininas conociendo el efecto de las primeras sobre las segundas.

La calidad de los explantes influye en la morfogénesis, mientras más joven sea el tejido, la micropropagación tendrá una mayor posibilidad de resultar exitosa, por ello se selecciona el material vegetal en óptimas condiciones fisiológicas y de saneamiento, sin olvidar el balance hormonal que también está asociado al estado de desarrollo del material vegetal.

La calidad de las plantas donadoras es un factor crítico que afectará el rendimiento del cultivo in vitro, por lo que, es conveniente estandarizar las condiciones de crecimiento previas al establecimiento aséptico, para asegurar la calidad de los explantes, los principales aspectos que se deben considerar son luz, temperatura, riego, fertilización y humedad, además de hacer constantes revisiones para eliminar plagas o enfermedades. Manteniendo estas condiciones de manera favorable se observar que las plantas madre se encuentran vigorosas y saludables.

\section{Agradecimientos}

Al Laboratorio de Biotecnología vegetal Unidad Marín de la Facultad de Agronomía de la UANL, por todas las facilidades brindadas en el desarrollo de la investigación. Y al Consejo Nacional de Ciencia y Tecnología (CONACYT) por la beca de manutención. 


\section{Literatura citada}

Arditti, J. 2008. Micropropagation of orchids, volume I. Blackwell Publishing. $2^{\text {th }}$ edition. USA. 300-327 pp.

Brandelli, A. and Lopes, C. 2005. Polyphenoloxidase activity browning potential and phenolic content of peaches during postharvest ripening. J. Food Biochem. 29(6):624-637.

Campbell, D. 2013. Orchidaceae, brief summary. Encyclopedia of life. http://eol.org/data_ objects/26748166.

Chang, C. and Chang, W. C. 1998. Plant regeneration from callus culture of Cymbidium ensifolium var. misericors. Plant Cell Reports. 17(4):251-255.

Chang, Y. K.; Veilleux, R. E. and Iqbal, M. J. 2009. Analysis of genetic variability among Phalaenopsis species and hybrids using amplified fragments length polymorphism. USA. J. Amer. Soc. Hort. Sct. 134(1):58-66.

Cumo, C. 2013. Encyclopedia of cultivated plants: from Acacia to Zinnia. Volume I. ABC-Clio. USA. 729-733 pp.

Feria, M.; Chávez, M. y Quiala, E. 2007. Establecimiento in vitro de Phalaenopsis. Biotecnología Vegetal. 1(7):27-33.

Flores, G.; Legaria, J.; Gil, I. y Colinas, M. 2008. Propagación in vitro de Oncidium stramineum Lindl. Una orquídea amenazada y endémica de México. Rev. Chapingo Ser. Hortic. 14(3):347-353.

Gamborg, O.; Mille, R. and Ojima, K. 1968. Nutrient requirements of suspension cultures of soybean root cells. Expt. Cell Res. 50(1):151-158.

George, E.; Hall, M. and De, K. G. 2008. Effects of physical environment. In: plant propagation by tissue culture. $3^{\text {th }}$. Springer. England. 423-464 pp.

González, M.; Mogollón, N.; Alvarado, G.; Giménez, A. y Capote T. 2012. Efecto del medo de cultivo in vitro y la fuente nitrogenada sobre el crecimiento del cocuy (Agave cocui Trelease). Bioagro. 24(1):39-44.

Gottschalk, A. 2012. Las orquídeas y su cultivo. http://www.paisajismotropical.com.

Gow, W. P.; Chen, J. T. and Chang, W. C. 2008. Influence of growth regulators on direct embryo formation from leaf explants of Phalaenopsis orchids. Acta Physiol Plant. 30:507-512. https://doi.org/10.1007/s11738-008-0148-4.

He, Y.; Guo, X.; Lu, R.; Niu, B.; Pasapula, V.; Hou, P.; Cai, F.; Xu, Y. and Chen, F. 2009. Changes in morphology and biochemical indices in browning callus derived from Jatropha curcas hypocotyls. Plant Cell, Tissue Organ Cult. 98(1):11-17.

Ibarra, A.; Ojeda, M. de C.; García E. y Gutierrez A. 2016. Inducción in vitro de brotes de dos cultivares de aguacate raza mexicana Persea americana var. drymifolia Schltdl. \& Cham. Rev. Mex. Cienc. Agríc. 7(2):337-347.

Jiménez, M. y Guevara E. 1996. Propagación in vitro de Phalaenopsis (Orchidaceae) mediante el cultivo de secciones de ejes florales después de la senescencia de las flores. Agron. Costarric. 20(1):75-79.

Knudson, L. 1946. A nutrient for germination of orchid seeds. American Orchid Society Bulletin. 15(9):214-217.

Košir, P.; Škof, S. and Luthar, Z. 2004. Direct shoot regeneration from nodes of Phalaenopsis orchids. Acta Agric. Slovenica. 83(2):233-242.

Krikorian, A. 1991. Medios de cultivo: generalidades, composición y preparación. Roca, W. and Mroginski, L. (Ed.). In: cultivo de tejidos en la agricultura: fundamentos y aplicaciones. Centro Internacional de Agricultura Tropical (CIAT). Colombia. Capítulo 3. 48-77. pp. 
Merino, M. 2014. Medio de cultivo. Hurtado, D. y Merino, M. (Ed.). In: cultivo de tejidos vegetales. Reimpresión de la $1^{\mathrm{a}}$ (Ed.). Editorial Trillas. México. Capítulo 5. 67-79 pp.

Murashige, T. and Skoog, F. 1962. A revised medium for rapid growth and bioassays with tobacco tissue cultures. Physiol. Plant. 15(3):473-497.

Nayak, N.; Susmita, S.; Satyanarayan, P. and Shiba, P. 2002. Establishment of thin cross section (TCS) culture method for rapid micropropagation of Cymbidium aloifolium (L.) Sw. and Dendrobium nobile Lindl. (Orchidaceae). Sci. Hortic. 94(1-2):107-116.

Nishimura, G. 1982. Japanese orchids. In: orchid biotechnology: reviews and perspectives II, Arditti, J. (Ed.). Orchid seed germination and seeding culture- a manual. Ithaca: Cornell University Press, New York. 331-346 pp.

Park, S. Y.; Hosakatte, N. M. and Kee, Y. P. 2002. Rapid propagation of Phalaenopsis from floral stalk-derived leaves. In Vitro Cell Dev Biol-Plant. 38(2):168-172.

Pequeño, I.; Martínez, G.; Aguirre, V.; Iracheta, L.; Mojica, V.; Rodríguez, G. y Ojeda, M. 2015. Efecto del $\mathrm{NaClO}$ sobre la actividad del polifenol oxidase en explantes de hoja y peciolo de dos genotipos de Jatropha curcas L. Bioagro. 27(3):167-172.

Preece, J. 2008. Stock plant physiological factors affecting growth and morphogenesis. George, E. M. H. and De Klerk, G. (Ed.). In: plant propagation by tissue culture volume I. $3^{\text {th }}$ Edition. Springer. Países Bajos. 403-422 pp.

Salazar, S.; Amaya A. y Barrientos, F. 2013. Evaluación de diferentes medios de cultivo in vitro en el desarrollo de híbridos de Phalaenopsis (Orchidaceae). Rev. Colomb. Biotecnol. 2(15):97-105.

Salgado, R.; López, R.; Martínez, M. y García, A. 2007. Biotecnología de plantas. Ciencia Nicolaita. 48:65-78.

Scalzo, J.; Politi, A.; Pellegrini, N.; Mezzetti, B. and Battino, M. 2005. Plant genotype affects total antioxidant capacity and phenolic contents in fruit. Nutrition. 21(2):207-213.

Taiz, L. and Zeiger, E. 2006. Plant physiology. $4^{\text {th }}$ (Ed.). Sinauer Associates, Inc. USA. 410-412 pp.

Tanaka, M. 1992. Micropropagation of Phalaenopsis spp. Bajaj, Y. P. S. (Ed.). In: Biotechnol. Agric. Forestry. Springer-Verlag. Berlin. Vol. 20. 246-268 pp.

Tirado, J.; Naranjo E. y Athortúa, L. 2005. Propagación in vitro de Phalaenopsis (orchidaceae) a partir de protocormos, mediante el sistema de inmersión temporal 'Rita'. Rev. Colomb. Biotecnol. 1(7):25-31.

Tokuhara, K. and Mii, M. 1993. Micropropagation of Phalaenopsis and Doritaenopsis by culturing shoot tips of flower stalk buds. Plant Cell Rep 13(1):7-11.

Trelka, T.; Brés, W.; Józwiak A. and Kozlowska, A. 2010. Phalaenopsis cultivation in different media. Part II. Nutrients and chlorophyll concentration in leaves and roots. Acta Sci. Pol. Hortorum Cultus. 9(3):95-104.

Vacin, E. and Went, F. 1949. Some pH changes in nutrient solutions. Bot Gaz. 110(4):605-613.

Villalobos, V. y Thorpe, T. 1991. Micropropagación: conceptos, metodología y resultados. Roca, W. y Mroginski, L. (Ed.). In: cultivo de tejidos en la agricultura: fundamentos y aplicaciones. Centro Internacional de Agricultura Tropical (CIAT). Colombia. Capítulo 6. 131-138 pp. 